Published in final edited form as:

Inorg Chem. 2019 June 03; 58(11): 7141-7145. doi:10.1021/acs.inorgchem.9b01036.

\title{
Self-assembled Amphiphilic Janus Double Metallacycle
}

\author{
Wenbo Wang ${ }^{\dagger, \perp}$, Zhixuan Zhou ${ }^{\ddagger}, \perp$, Jiong Zhou ${ }^{\dagger}$, Bingbing Shi ${ }^{\ddagger}$, Bo Song ${ }^{\S}$, Xiaopeng Li ${ }^{\S}$, \\ Feihe Huang ${ }^{*}, \dagger$, Peter J. Stang ${ }^{*}, \neq$ \\ †State Key Laboratory of Chemical Engineering, Center for Chemistry of High-Performance \& \\ Novel Materials, Department of Chemistry, Zhejiang University, Hangzhou 310027, P. R. China \\ ‡Department of Chemistry, University of Utah, 315 South 1400 East, Room 2020, Salt Lake City, \\ Utah 84112, United States \\ §Department of Chemistry, University of South Florida, 4202 East Fowler Avenue, Tampa, Florida \\ 33620, United States
}

\begin{abstract}
A double metallacycle was prepared via the size-selective integrative self-sorting of four different building blocks driven by a reversible metal-ligand coordination interaction. A hydrophobic dendron was placed on a metallacycle and a hydrophilic dendron was attached to the other metallacycle, producing a two-faced Janus-type supramolecule with two distinct functionalities. In aqueous media, hierarchical self-assembly of the supramolecular system was induced by the combination of coordination interactions and hydrophobic-hydrophilic interactions resulting in the formation of micrometer-sized fiber-like structures, a morphology distinct from metallacycles bearing only one type of functionality. This study provides a versatile approach for the construction of Janus-type molecules and demonstrates that integrative self-sorting of a supramolecular coordination system can be utilized for the preparation of complex supramolecular systems with pre-designed functionalities and morphologies
\end{abstract}

\section{Graphical Abstract}

Coordination-driven self-assembly of Janus double metallacycle by the integrative self-sorting of four different precursors. A hydrophobic dendron was placed on a metallacycle and a hydrophilic dendron was attached to the other metallacycle, producing a two-faced Janus-type supramolecule with two distinct functionalities. Further self-assembly of the metallacycle in aqueous media lead to the formation of a large fiber-like morphology.

\footnotetext{
*Corresponding Author fhuang@ zju.edu.cn, stang@chem.utah.edu.

$\perp$ These authors contributed equally.

Supporting Information

Detailed materials and methods. Synthesis and characterization of building blocks and metallacycles. The Supporting Information is available free of charge on the ACS Publications website.

The authors declare no competing financial interests.
} 


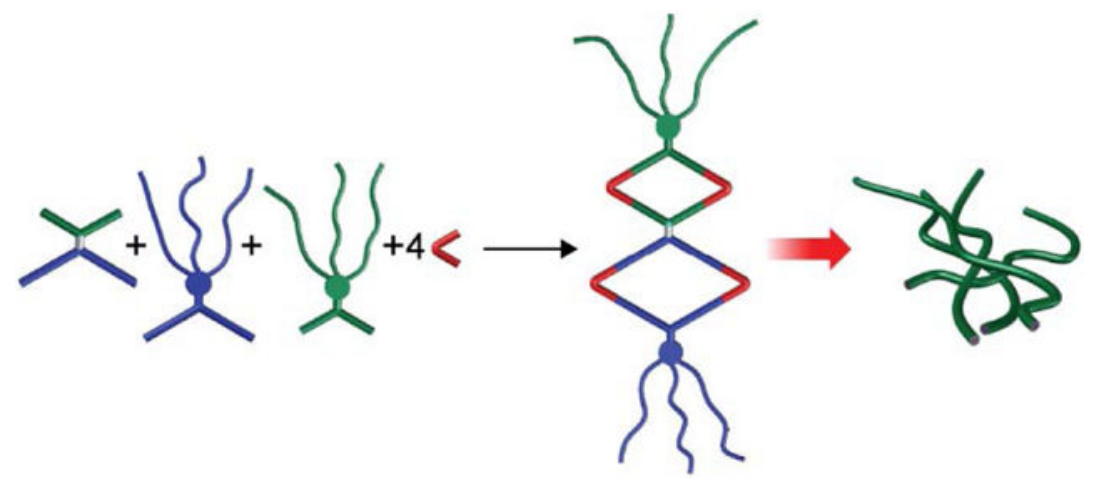

Coordination-driven self-assembly is a powerful methodology for the rational design and synthesis of various discrete supramolecular systems using small and simple molecular building blocks. ${ }^{1}$ With the development of synthetic and topological aspects of the selfassembled systems, the functions of the supramolecules have received increasing interest, and applications in separation, ${ }^{2}$ catalysis, ${ }^{3}$ polymer synthesis, ${ }^{4}$ biomedicine, ${ }^{5}$ etc. ${ }^{6}$ These self-assembled systems are mostly constructed via the combination of complementary pairs of two highly symmetric building blocks, thus ensuring the exclusive formation of a single product. As a result, the number of functionalities of these supramolecular systems is often limited.

In order to introduce multiple functionalities to a supramolecular system to achieve the same high-level functional complexity observed in various biomolecules, self-sorting of complex systems is often employed. Self-sorting can be defined as high fidelity recognition between molecules (and ions) within complex mixtures. ${ }^{7}$ The precise control over the self-sorting process of a complex supramolecular system could lead to the formation of products with a greater structural and functional complexity than simple self-assembled systems. ${ }^{8}$ For supramolecular systems based on coordination-driven interactions, the heteroligation of metal ions may enable the formation of multicomponent cages via integrative self-sorting, ${ }^{9}$ yet the functional groups attached to the ligands may influence the self-sorting outcomes. ${ }^{9 \mathrm{~d}}$ In contrast, the self-sorting organoplatinum(II)-based systems are mainly directed by the size and shape of the constituent building blocks. ${ }^{10}$ These studies focused on non-integrative (narcissistic) systems to establish the principle of self-sorting, ${ }^{10-11}$ whereas integrative systems remained unexplored but have the potential for singular, multifunctional assemblies.

Janus molecules are molecules bearing two chemically distinct functionalities, resulting in different chemical or physical properties localized at distinct parts of the same molecule. ${ }^{12}$ Janus molecules have great potential as building blocks for self-assembly due to their asymmetric structure and functionalization, and has inspired widespread applications in biotechnology ${ }^{13}$ and materials science. ${ }^{14}$ The synthesis of Janus molecules relies on covalent bond formation that often involves tedious multistep syntheses and challenging separation that limit the expansion of Janus molecules libraries for the further understanding of structure-property relationships of these molecules .

Herein, an amphiphilic Janus supramolecule was prepared via the self-sorting of an organoplatinum (II)-based coordination system. An asymmetric, tetrapyridyl ligand $\mathbf{1}$ was 
prepared by connecting two dipyridyl ligands with different sizes as the bridging motif for the double metallacycle. Size-selective integrative self-sorting of ligand $\mathbf{1}$ with dipyridyl ligands bearing distinct sizes and functionalities (a hydrophobic, octyloxy chain-containing dendron for $\mathbf{2}$ or a hydrophilic, tri(ethylene oxide)-containing dendron for $\mathbf{3}$ ) and complementary organoplatinum(II) building block 4 in a 1:1:1:4 ratio lead to the formation of a double metallacycle 5 bearing two dendrons with distinct properties attached to opposite sides of the metallacycle core (Scheme 1). Metallacycles bearing only hydrophobic dendrons (6) or hydrophilic dendrons (7) were prepared via the $2+2$ coordination-driven self-assembly between the dipyridyl ligand $\mathbf{2}$ or $\mathbf{3}$ with $\mathbf{4}$ (Figures S14-S21) as reference compounds for examing the fidelity of the size-selective self-sorting process.

To confirm that the size of the building blocks was the determining factor during the selfsorting process of the supramolecular system, building blocks $\mathbf{2}, \mathbf{3}$, and $\mathbf{4}$ were mixed in a 2:2:4 ratio. The ${ }^{1} \mathrm{H}$ NMR spectra of the reaction mixture exhibited peaks corresponding to metallacycles $\mathbf{6}$ and $\mathbf{7}$ under the same conditions, with no broad peaks and unassignable signals (Figure 1a). Similarly, two peaks corresponding to metallacycles $\mathbf{6}$ and $\mathbf{7}$ at 14.90 ppm and $14.72 \mathrm{ppm}$, respectively, were observed in the ${ }^{31} \mathrm{P}$ NMR spectra of the reaction mixture (Figure S22). These results indicate the formation of $\mathbf{6}$ and $\mathbf{7}$ as the predominant products in the solution via the size-selective, narcissistic self-sorting of the supramolecular system.

Because the asymmetric ligand $\mathbf{1}$ was used for the synthesis, the ${ }^{1} \mathrm{H}$ and ${ }^{31} \mathrm{P}$ NMR spectra of the Janus double metallacycle 5 exhibit complicated, broad signals (Figures $1 \mathrm{~b}$ and S12). Diffusion-ordered NMR spectroscopy (DOSY) study on $\mathbf{5}$ suggested a single ensemble with a band at the diffusion coefficient of $D=6.6 \times 10^{-11} \mathrm{~m}^{2} \cdot \mathrm{s}^{-1}$ (Figures $1 \mathrm{c}$ and S11). This value is significantly lower compared to that of the $2+2$ metallacycles $6\left(D=1.2 \times 10^{-10} \mathrm{~m}^{2} \cdot \mathrm{s}^{-1}\right)$ (Figure S15) and $7\left(D=1.7 \times 10^{-10} \mathrm{~m}^{2} \cdot \mathrm{s}^{-1}\right)$ (Figure S19), indicating the formation of a larger product relative to the single metallacycles via integrative self-sorting. ${ }^{15}$ The composition of 5 was further confirmed using electrospray ionization mass spectrometry (ESI-MS).

Prominent peaks corresponding to the intact compound 5 with $+4,+5$, and +6 charge states were observed due to the loss of the nitrate $\left(\mathrm{ONO}_{2}\right)$ counterions at $\mathrm{m} / \mathrm{z}=1645.89,1304.28$, and 1076.52, respectively (Figure 2). These peaks were isotopically resolved and showed good agreement with the theoretical distributions. Peaks that corresponds to fragments of 5 were also observed, likely due to the decomposition and re-assembly of the building blocks in the ESI-MS measurement.

Inspired by the amphiphilic nature of $\mathbf{5}$, the aggregation behavior of the metallacycles were studied by conductivity measurements of the aqueous solutions of the metallacycles at different concentrations (Figure 3). The critical aggregation concertation (CAC) of 5 was determined to be $1.11 \times 10^{-6} \mathrm{M}$. In contrast, the $\mathrm{CAC}$ of the hydrophilic dendronfunctionalized metallacycle 7 was $5.17 \times 10^{-7} \mathrm{M}$, which is slightly lower compared to the CAC of 5. A Tyndall effect was observed for the aqueous solutions of $\mathbf{5}$ and $\mathbf{7}$ at concentrations higher than their respective CACs (Figure S23), indicating the existence of aggregates. 
Transmission electron microscopy (TEM) was used to visualize the aggregates of metallacycles $\mathbf{5}$ and $\mathbf{7}$ at concentrations higher than their respective CACs. Large fiber-like structures with widths of $300 \mathrm{~nm}$ and lengths of ${ }^{\prime} 5 \mu \mathrm{m}$ were observed upon self-assembly of 5 (Figure 4a-b). Similar morphology is observed for both metallacycles in scanning electron microscopy (SEM) experiments (Figure S25-S26). A possible mechanism for the formation of the fiber-like morphology involves a bilayer structure formed by the hierarchical selfassembly of the supramolecular system. The first level of organization is the formation of the double metallacycles 5 by metal-ligand coordination that placed the distinct dendrons on opposite sides of the ensemble. Higher level organization originated from the amphiphilic nature of $\mathbf{5}$ and the stacking interactions between the $\pi$ systems of the metallacycle core. The hydrophilic-hydrophobic interactions drove the hydrophobic dendrons to the interior of the assembly, whereas the hydrophilic dendrons existed on the exterior of the ensemble, and $\pi-\pi$ stacking interactions between the metallacycles provided ordering to form a fiber-like double-sandwich structure (Figure 4e). In contrast, spherical nanoparticles with diameter of $\sim 200 \mathrm{~nm}$ were observed upon aggregation of 7 in aqueous solution (Figure 4c-d). Dynamic light scattering (DLS) experiment of an aqueous solution of 7 shows an average hydrodynamic diameter of $127.4 \pm 8.4 \mathrm{~nm}$ (Figure S24), in agreement with the TEM results. With two hydrophilic dendrons located on opposite vertices of its rhomboidal structure, metallacycle 7 is a bola-type amphiphile ${ }^{16}$ and the particles were formed via metallacycle ordering and extension of the hydrophilic dendrons from the metallacycle core (Figure 4f). These observations suggest divergent aggregation behavior between $\mathbf{5}$ and $\mathbf{7}$ originating from their distinct type and placement of the constituent functional groups.

In summary, utilizing size-selective integrative self-sorting of a four-component supramolecular coordination system, a Janus double metallacycle was prepared with high efficiency. Dendrons with distinct hydrophobicities were placed on opposite vertices of the double metallacycle, endowing the supramolecule with an amphiphilic nature. Hierarchical self-assembly of the supramolecular system was achieved by the synergy of metal-ligand coordination interactions between the pyridyl groups and organoplatinum (II), as well as the hydrophobic-hydrophilic interactions between the dendrons, resulting in the formation of a large fiber-like morphology. In contrast, spherical nanoparticles were observed by hierarchical self-assembly of the metallacycle bearing only one type of dendron. This study represents an alternative approach for building Janus-type molecules, and the modularity of coordination-driven self-assembly may be beneficial for the expansion of Janus-type molecule libraries to improve our understanding of their unique structure-property relationships. Moreover, this study provides a general strategy for the rational design and synthesis of multifunctional supramolecular systems via integrative self-sorting.

\section{Supplementary Material}

Refer to Web version on PubMed Central for supplementary material.

\section{ACKNOWLEDGMENT}

This work was supported by the National Nature Science Foundation of China (21620102006). P.J.S. thanks NIH (Grant R01 CA215157) for financial support. X.L. thanks the NSF (CHE-1506722) and NIH (R01GM128037) for their support. 


\section{REFERENCES}

1 (a). Chakrabarty R; Mukherjee PS; Stang PJ Supramolecular Coordination: Self-Assembly of Finite Two- and Three-Dimensional Ensembles. Chem. Rev. 2011, 111, 6810. [PubMed: 21863792] (b)Harris K; Fujita D; Fujita M Giant Hollow Mnl2n Spherical Complexes: Structure, Functionalisation and Applications. Chem. Commun. 2013, 49.(c)Huang S-L; Hor TSA; Jin G-X Metallacyclic Assembly of Interlocked Superstructures. Coord. Chem. Rev. 2017, 333, 1.(d)Gan M-M; Liu J-Q; Zhang L; Wang Y-Y; Hahn FE; Han Y-F Preparation and Post-Assembly Modification of Metallosupramolecular Assemblies from Poly(N-Heterocyclic Carbene) Ligands. Chem. Rev. 2018, 118, 9587. [PubMed: 29975040] (e)Ward MD; Hunter CA; Williams NH Coordination Cages Based on Bis(Pyrazolylpyridine) Ligands: Structures, Dynamic Behavior, Guest Binding, and Catalysis. Accounts of Chemical Research 2018, 51, 2073. [PubMed: 30085644] (f)Chakraborty S; Newkome GR Terpyridine-Based Metallosupramolecular Constructs: Tailored Monomers to Precise 2d-Motifs and 3d-Metallocages. Chem. Soc. Rev. 2018, 47, 3991. [PubMed: 29594272] (g)Pan M; Wu K; Zhang J-H; Su C-Y Chiral MetalOrganic Cages/Containers (Mocs): From Structural and Stereochemical Design to Applications. Coordination Chemistry Reviews 2019, 378, 333.

2 (a). Zhang D; Ronson TK; Mosquera J; Martinez A; Nitschke JR Selective Anion Extraction and Recovery Using a Feii414 Cage. Angew. Chem. Int. Ed. 2018, 57, 3717.(b)Li X-Z; Zhou L-P; Yan L-L; Dong Y-M; Bai Z-L; Sun X-Q; Diwu J; Wang S; Bünzli J-C; Sun Q-F A Supramolecular Lanthanide Separation Approach Based on Multivalent Cooperative Enhancement of Metal Ion Selectivity. Nat. Commun. 2018, 9.

3 (a). Brown CJ; Toste FD; Bergman RG; Raymond KN Supramolecular Catalysis in Metal-Ligand Cluster Hosts. Chem. Rev. 2015, 115, 3012. [PubMed: 25898212] (b)Oldacre AN; Friedman AE; Cook TR A Self-Assembled Cofacial Cobalt Porphyrin Prism for Oxygen Reduction Catalysis. J. Am. Chem. Soc. 2017, 139, 1424. [PubMed: 28102678] (c)Sinha I; Mukherjee PS Chemical Transformations in Confined Space of Coordination Architectures. Inorg. Chem. 2018, 57, 4205. [PubMed: 29578701] (d)Jongkind LJ; Caumes X; Hartendorp APT; Reek JNH Ligand Template Strategies for Catalyst Encapsulation. Acc. Chem. Res. 2018, 51, 2115. [PubMed: 30137959] (e)Preston D; Sutton JJ; Gordon KC; Crowley JD A Nona-Nuclear Heterometallic Pd3pt6 "Donut"-Shaped Cage: Molecular Recognition and Photocatalysis. Angew. Chem. Int. Ed. 2018, 57, 8659.(f)Holloway LR; Bogie PM; Lyon Y; Ngai C; Miller TF; Julian RR; Hooley RJ Tandem Reactivity of a Self-Assembled Cage Catalyst with Endohedral Acid Groups. J. Am. Chem. Soc. 2018, 140, 8078. [PubMed: 29913069] (g)Zhao L; Jing X; Li X; Guo X; Zeng L; He C; Duan C Catalytic Properties of Chemical Transformation within the Confined Pockets of Werner-Type Capsules. Coord. Chem. Rev. 2019, 378, 151.

4 (a). Chen L-J; Yang H-B Construction of Stimuli-Responsive Functional Materials Via Hierarchical Self-Assembly Involving Coordination Interactions. Acc. Chem. Res. 2018, 51, 2699. [PubMed: 30285407] (b)Gu Y; Alt EA; Wang H; Li X; Willard AP; Johnson JA Photoswitching Topology in Polymer Networks with Metal-Organic Cages as Crosslinks. Nature 2018, 560, 65. [PubMed: 30022167]

5 (a). Therrien B Biologically Relevant Arene Ruthenium Metalla-Assemblies. CrystEngComm 2015, 17, 484.(b)Casini A; Woods B; Wenzel M The Promise of Self-Assembled 3d Supramolecular Coordination Complexes for Biomedical Applications. Inorg. Chem. 2017, 56, 14715. [PubMed: 29172467] (c)Samanta SK; Quigley J; Vinciguerra B; Briken V; Isaacs L Cucurbit[7]Uril Enables Multi-Stimuli-Responsive Release from the Self-Assembled Hydrophobic Phase of a Metal Organic Polyhedron. J. Am. Chem. Soc. 2017, 139, 9066. [PubMed: 28621947] (d)Wang H; Qian X; Wang K; Su M; Haoyang W-W; Jiang X; Brzozowski R; Wang M; Gao X; Li Y; Xu B; Eswara P; Hao X-Q; Gong W; Hou J-L; Cai J; Li X Supramolecular Kandinsky Circles with High Antibacterial Activity. Nat. Commun. 2018, 9.

6 (a). Croué V; Goeb S; Sallé M Metal-Driven Self-Assembly: The Case of Redox-Active Discrete Architectures. Chemical Communications 2015, 51, 7275. [PubMed: 25812077] (b)Jansze SM; Severin K Clathrochelate Metalloligands in Supramolecular Chemistry and Materials Science. Accounts of Chemical Research 2018, 51, 2139. [PubMed: 30156828] (c)Zhu R; Regeni I; Holstein JJ; Dittrich B; Simon M; Prévost S; Gradzielski M; Clever GH Catenation and Aggregation of Multi-Cavity Coordination Cages. Angew. Chem. Int. Ed. 2018, 57, 13652.(d)Li 
M; Chen L-J; Cai Y; Luo Q; Li W; Yang H-B; Tian H; Zhu W-H Light-Driven Chiral Switching of Supramolecular Metallacycles with Photoreversibility. Chem 2019, 5, 634.

7 (a). Wu A; Isaacs L Self-Sorting: The Exception or the Rule? J. Am. Chem. Soc. 2003, 125, 4831. [PubMed: 12696902] (b)Safont-Sempere MM; Fernández G; Würthner F Self-Sorting Phenomena in Complex Supramolecular Systems. Chem. Rev. 2011, 111, 5784. [PubMed: 21846150]

8 (a). Lal Saha M; Schmittel M Degree of Molecular Self-Sorting in Multicomponent Systems. Org. Biomol. Chem. 2012, 10, 4651. [PubMed: 22543924] (b)Saha ML; De S; Pramanik S; Schmittel M Orthogonality in Discrete Self-Assembly - Survey of Current Concepts. Chem. Soc. Rev. 2013, 42, 6860. [PubMed: 23756556] (c)He Z; Jiang W; Schalley CA Integrative Self-Sorting: A Versatile Strategy for the Construction of Complex Supramolecular Architecture. Chem. Soc. Rev. 2015, 44, 779. [PubMed: 25374006]

9 (a). Zheng Y-R; Zhao Z; Wang M; Ghosh K; Pollock JB; Cook TR; Stang PJ A Facile Approach toward Multicomponent Supramolecular Structures: Selective Self-Assembly Via Charge Separation. J. Am. Chem. Soc. 2010, 132, 16873. [PubMed: 21053935] (b)Bloch WM; Clever GH Integrative Self-Sorting of Coordination Cages Based on 'Naked' Metal Ions. Chem. Commun. 2017, 53, 8506.(c)Holloway LR; Bogie PM; Hooley RJ Controlled Self-Sorting in Self-Assembled Cage Complexes. Dalton Trans. 2017, 46, 14719. [PubMed: 29018845] (d)Saha S; Holzapfel B; Chen Y-T; Terlinden K; Lill P; Gatsogiannis C; Rehage H; Clever GH Rational Design of an Amphiphilic Coordination Cage-Based Emulsifier. J. Am. Chem. Soc. 2018, 140, 17384. [PubMed: 30516378]

10. Northrop BH; Zheng Y-R; Chi K-W; Stang PJ Self-Organization in Coordination-Driven SelfAssembly. Acc. Chem. Res. 2009, 42, 1554. [PubMed: 19555073]

11 (a). Zheng Y-R; Yang H-B; Northrop BH; Ghosh K; Stang PJ Size Selective Self-Sorting in Coordination-Driven Self-Assembly of Finite Ensembles. Inorg. Chem. 2008, 47, 4706. [PubMed: 18433099] (b)Wang W; Zhang Y; Sun B; Chen L-J; Xu X-D; Wang M; Li X; Yu Y; Jiang W; Yang H-B The Construction of Complex Multicomponent Supramolecular Systems Via the Combination of Orthogonal Self-Assembly and the Self-Sorting Approach. Chem. Sci. 2014, $5,4554$.

12 (a). Branda N; Kurz G; Lehn J-M Janus Wedges: A New Approach Towards Nucleobase-Pair Recognition. Chem. Commun. 1996, 2443.(b)Ropponen J; Nummelin S; Rissanen K Bisfunctionalized Janus Molecules. Org. Lett. 2004, 6, 2495. [PubMed: 15255674] (c)Caminade A-M; Laurent R; Delavaux-Nicot B; Majoral J-P “Janus” Dendrimers: Syntheses and Properties. New J. Chem. 2012, 36, 217.

13 (a). Robinson CJ; Vincent HA; Wu M-C; Lowe PT; Dunstan MS; Leys D; Micklefield J Modular Riboswitch Toolsets for Synthetic Genetic Control in Diverse Bacterial Species. J. Am. Chem. Soc. 2014, 136, 10615. [PubMed: 24971878] (b)Piao X; Xia X; Mao J; Bong D Peptide Ligation and Rna Cleavage Via an Abiotic Template Interface. J. Am. Chem. Soc. 2015, 137, 3751. [PubMed: 25747470] (c)Sherman SE; Xiao Q; Percec V Mimicking Complex Biological Membranes and Their Programmable Glycan Ligands with Dendrimersomes and Glycodendrimersomes. Chem. Rev. 2017, 117, 6538. [PubMed: 28417638]

14 (a). Lee CC; Gillies ER; Fox ME; Guillaudeu SJ; Frechet JMJ; Dy EE; Szoka FC A Single Dose of Doxorubicin-Functionalized Bow-Tie Dendrimer Cures Mice Bearing C-26 Colon Carcinomas. Proc. Natl. Acad. Sci. USA 2006, 103, 16649. [PubMed: 17075050] (b)Percec V; Wilson DA; Leowanawat P; Wilson CJ; Hughes AD; Kaucher MS; Hammer DA; Levine DH; Kim AJ; Bates FS; Davis KP; Lodge TP; Klein ML; DeVane RH; Aqad E; Rosen BM; Argintaru AO; Sienkowska MJ; Rissanen K; Nummelin S; Ropponen J Self-Assembly of Janus Dendrimers into Uniform Dendrimersomes and Other Complex Architectures. Science 2010, 328, 1009. [PubMed: 20489021] (c)Walther A; Müller AHE Janus Particles: Synthesis, Self-Assembly, Physical Properties, and Applications. Chem. Rev. 2013, 113, 5194. [PubMed: 23557169] (d)Roy N; Bruchmann B; Lehn J-M Dynamers: Dynamic Polymers as Self-Healing Materials. Chem. Soc. Rev. 2015, 44, 3786. [PubMed: 25940832] (e)Deng R; Liang F; Zhu J; Yang Z Recent Advances in the Synthesis of Janus Nanomaterials of Block Copolymers. Mater. Chem. Front. 2017, 1, 431. 
15. Megyes T; Jude H; Grósz T; Bakó I; Radnai T; Tárkányi G; Pálinkás G; Stang PJ X-Ray Diffraction and Dosy Nmr Characterization of Self-Assembled Supramolecular Metallocyclic Species in Solution. J. Am. Chem. Soc. 2005, 127, 10731. [PubMed: 16045362]

16 (a). Zhang X; Wang C Supramolecular Amphiphiles. Chem. Soc. Rev. 2011, 40, 94. [PubMed: 20890490] (b)Yan XZ; Li SJ; Cook TR; Ji XF; Yao Y; Pollock JB; Shi YH; Yu GC; Li JY; Huang FH; Stang PJ Hierarchical Self-Assembly: Well-Defined Supramolecular Nanostructures and Metallohydrogels Via Amphiphilic Discrete Organoplatinum(Ii) Metallacycles. J. Am. Chem. Soc. 2013, 135, 14036. [PubMed: 23927740] (c)Jie K; Zhou Y; Yao Y; Huang F Macrocyclic Amphiphiles. Chem. Soc. Rev. 2015, 44, 3568. [PubMed: 25868640] 

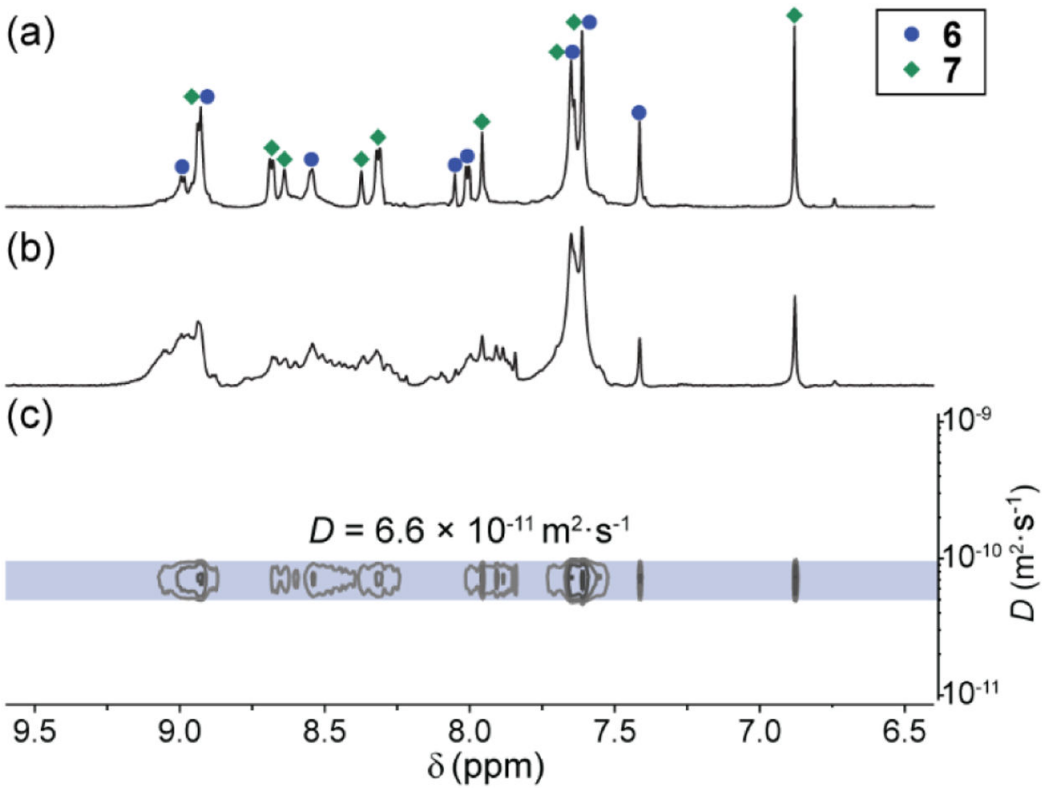

Figure 1.

(a) Partial ${ }^{1} \mathrm{H}$ NMR spectrum $\left(500 \mathrm{MHz}, \mathrm{DMSO}-d_{6}, 298 \mathrm{~K}\right)$ of equimolar mixture of metallacycles 6 and $7(c=2.0 \mathrm{mM})$. (b) Partial ${ }^{1} \mathrm{H}$ NMR spectrum (500 MHz, DMSO- $d_{6}$, $298 \mathrm{~K})$ of $5(c=2.0 \mathrm{mM})$. (c) Partial ${ }^{1} \mathrm{H}$ DOSY spectrum (500 MHz, DMSO- $d_{6}, 298 \mathrm{~K}$ ) of 5. 


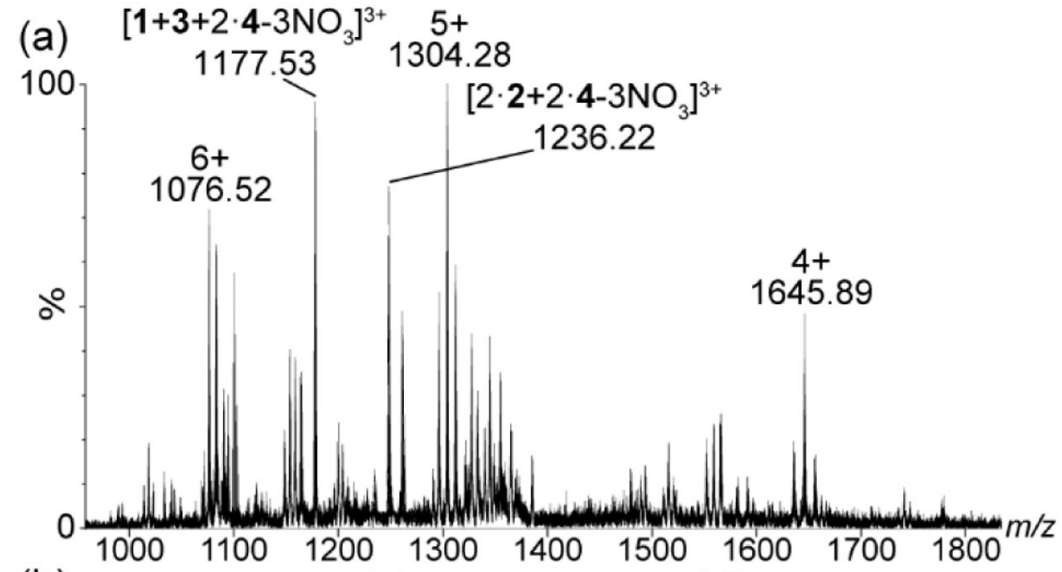

(b)

(c)

Theoretical

$5+$

(d)

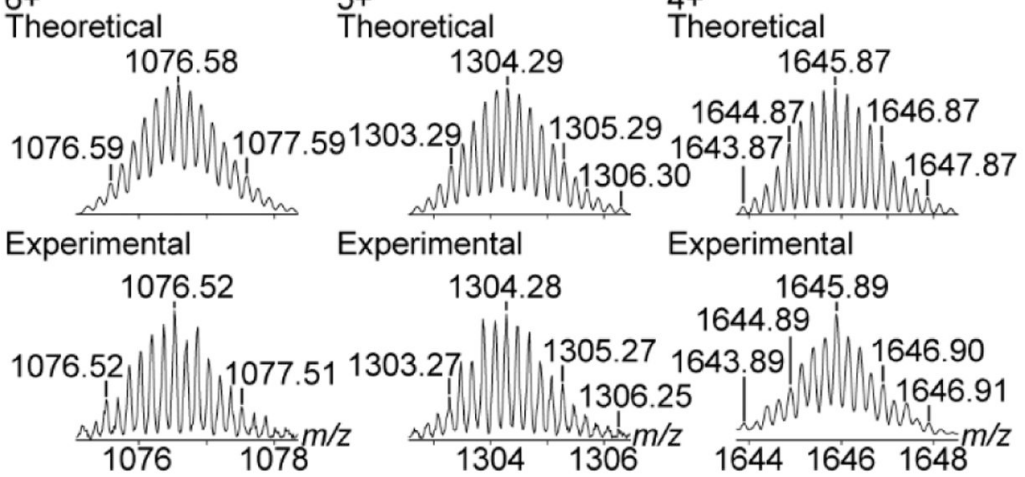

Figure 2.

(a) ESI-MS spectrum of double metallacycle 5. (b-d) Expanded experimental (bottom) and theoretical (top) spectra of the $6+($ b), $5+(\mathrm{c})$, and $4+(\mathrm{d})$ charge states. 
(a)

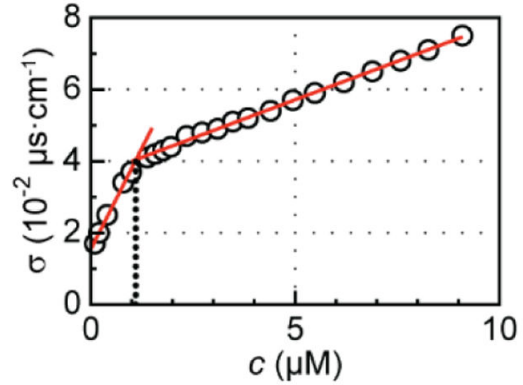

(b)

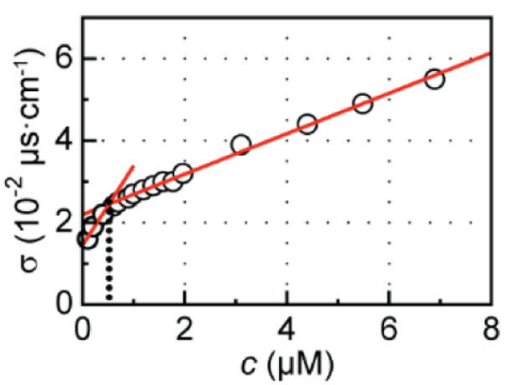

Figure 3.

Concentration-dependent conductivity changes of 5 (a) and 7 (b). 

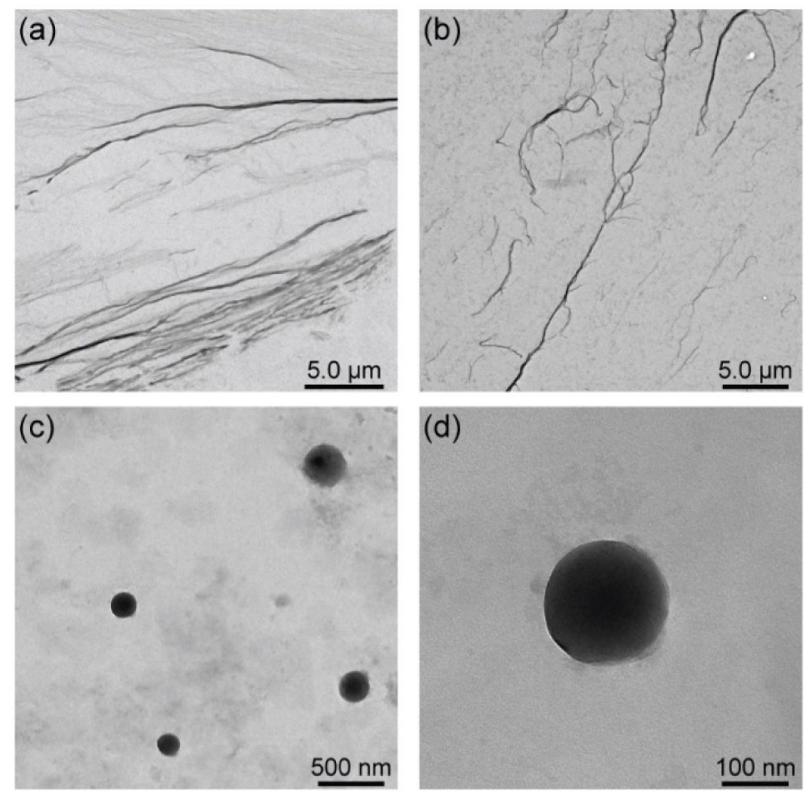

(e)

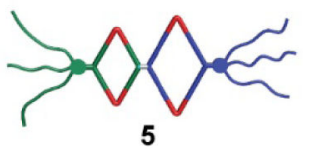

(f)
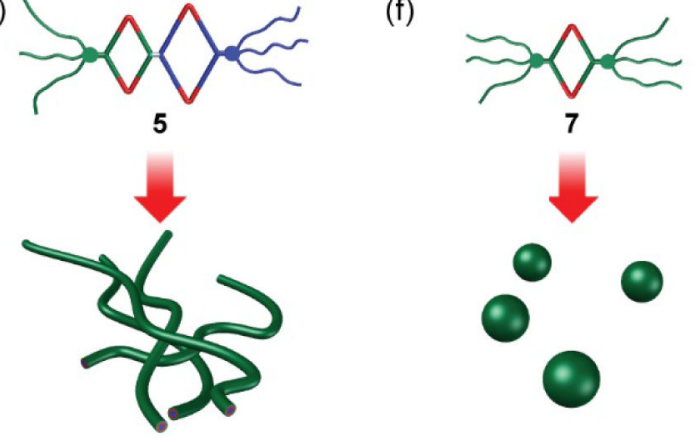

Figure 4.

(a-d) TEM images of self-assembled structure formed by $5(a-b)\left(c=1.0 \times 10^{-4} \mathrm{M}\right)$ and 7 (c-d) $\left(c=1.0 \times 10^{-4} \mathrm{M}\right)$ in aqueous media. (e-f) Proposed mechanism for hierarchical selfassembly of 5 (e) and 7 (f) in aqueous media. 

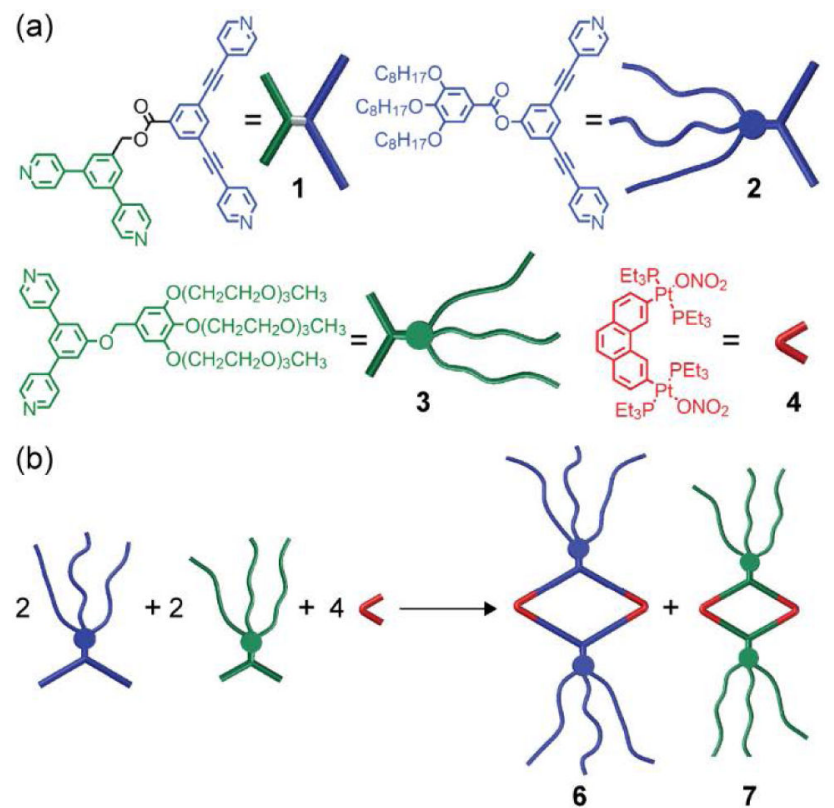

Hydrophobic Hydrophilic Size-Selective Narcissistic Self-Sorting

(c)

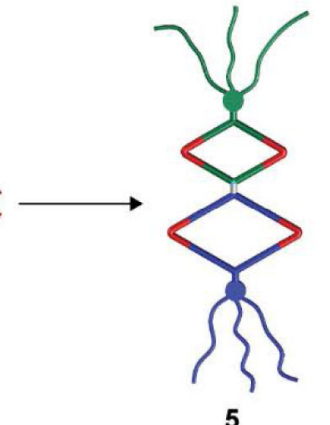

Hydrophobic + Hydrophilic

Size-Slective Integrative Self-Sorting

\section{Scheme 1.}

(a) Structure of the Building Blocks Used in Self-Assembly. (b) Size-Selective Narcissistic Self-Sorting of Metallaccyles 6 and 7. (c) Integrative Self-Sorting for the Preparation of Janus Metallacycle 5. 